OUR ASTRONOMICAL COLUMN.

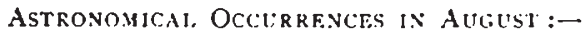

August 8. 10h. $7 \mathrm{~m}$. to 10h. $44 \mathrm{~m}$. Occultation of $\mu$ Arietis (mag. 5.8 ) by the moon.

8. Saturn. Outer minor axis of outer ring, $17^{\prime \prime} \cdot 37$.

8. 15h. Mercury at greatest elongation $\left(27^{\circ} 22^{\prime}\right.$ E. $)$.

10. Meteoric shower from Perseus (radiant $45^{\circ}+57^{\circ}$ )

1I. $14 \mathrm{~h} .49 \mathrm{~m}$ to $15 \mathrm{~h}$. $38 \mathrm{~m}$. Occultation of 118 Tauri (mag. 5.4) by the moon.

12. $12 \mathrm{~h} .3 \mathrm{Im}$. to $13 \mathrm{~h}$. $19 \mathrm{~m}$. ()ccultation of 8 (jemi. norum (mag. 6.5) by the monn.

15. Venus. Illuminated portion $=0655$, diameter $=$ $17^{\prime \prime} 4$. 15. Mars. Illuminated portion $=0.889$, liameter $=$

15. Jupiter. Polar diameter $=29 " 8$.

15. Saturn. " " $=15^{\prime \prime} 8$.

19. 6h. Venus in" conjunction with Jupiter (Venus $i^{\circ} 5 \mathrm{I}^{\prime} \mathrm{S}$.).

23. 9h. $32 \mathrm{~m}$. Minimum of Algol (B Persei).

25. Ioh. Mars in conjunction with Neptune (Mars $I^{\circ}$ I $\left.3^{\prime} \times\right)$.

28. $12 \mathrm{~h}$. $53 \mathrm{~m}$. to $\mathrm{r}_{3 \mathrm{~h}} \cdot 43^{\mathrm{m}}$. Occultation of $\sigma$ Capricorni (mag. $5^{\circ} 6$ ) by the moon.

THE: MINOR PIANEIS,-Mr. John K. Kees, in a lecture before the New lork Academy of Sciences iSchool of Mines Quarterly, vol. xix. No. 3), delivered a very interesting discourse on the history of the discovery of the minor planets, a reprint of which has heen sent to us. Mr. Rees describes from the beginning how, after the discovery of Liranus by Herschel, J'rof. Titius, of IVittenberg, pointed out the existence of a remark. able symmetry in the dispusition of the bodies constituting the solar system. It was he wbo suggested the relationship now known as "Bode's law," P'rof. Bode putting into the place of the missing body a hypothetical planct. It is not generaliy known, perhajs, that Von Zach in 1785 actually calculaterl elements for this "unseen and unfelt body," and fur fifteen years kept in his mind the nced for a careful scarch. At the beginning of this century he organised, what was termed jocularly' by him the "Celestial Police" to trach and intercept this fugitive object, a force for the express purpose of systematically scanning the heavens; but it was left for the astronomer, l'iazzi, who found the first of what eventually provecl a series of small lindies, although he was carefully observing the heavens for quite another purpose, namely the formation of a star catalugue. 'This discovery of the minor planet Ceres was the first of many which folluwed, and the introduction of photography in this branch of observation has brought to light many small bodies which are now numbered in hundreds, besides rendering the task, which was beset with great difficulties, one that is now simplicity itseif.

THF Moox AND Aurok.t.-From the earliest times the presence of auroric was in some way connected with the influence of the moon, and there may be some, even to-day, who are inclined 10 hold to this opinion. I'rof. H. A. Hazen, in the Monthly Weather K'eriere (vol. xxvi. No. 161), discusses the evidence of such supposed influence, using as his data the observations made by the regular observers in the United States Signal Service. We need not, however, refer to the curves and tables which are brought together by l'rof. Hazen, but simply quote the words which he uses in sumıning up the whole of the investigation in question. He says: "It will be seen readily that the whole theory of a lunar infuence upon auroras breaks down from first to last under this analysis." That the appear. ances of aurorie may be connected with the periodicity of sunspots is another matter, and it is here that probably a close connection exists.

Anropos of aurore, we notice that l'rof Clevelard Abhe is publishing a very detailed and important historical account of the altitucle of aurorix: atove the carth's surface as determined by observers all over the worid. The first of these articles appeass in Tervestrial Mfagnetism (vol, iii. No. 2), and is well worth reading by those who are interested in this important question.

Mars in I 896 -7.-Prof. V. Cerulli has just pulslished, in the Putblicazioni dell" Osseratatorio priarato di Collurania (Teramo) (No. 1), a most important memoir of the planet Mars, as observed by him during the period i $\$ 96-7$. The volume covers NO. I 500, VOI. 58$]$ no less than I 26 pages, and is accompanied by numerous plates forming a valuable adrition to our knowiledge of this interesting planet. P'erhaps a special feature of this putlication is the determination of the latitudes and longitudes of sixty of the most prominent markings on the surface: and this will, without doubt, he found most valualile to those who wish to locate accurately any surface features which they may from time in time observe. In the remaining portion of the work l'rof. Ceruili discusses these and other surface markings which were seen during this period of olservation, and a comparison of these with the observations of uthers should be found of great interest.

\section{RECENT WORK IN THERMOMETRY}

THERMOMITRY is one of those departments of physics which are left almost exclusively to specialists, and writings on the subject are apt to assume an an:ount of preliminary know. ledge nut possessed lyy physicists in general. There thus appears rnom for a brief account in popular language of recent progress. The space at my disposal being linited, I am obliged to confine nyy remarks to a comparatively snall number of researches, and I can harrlly hope that my choice of matter will meet with un. mixed a provial.

Thermometry possesses two main branches, which, though intimately connected, are yet more or less distinct. One liranch deals with the detection of extremely minute differ. ences of temperature, or the suldrivision of sniall temperature intervals; the other ains at assigning a definite numerical value to temperatures on an exact scale. A worker in the first department may employ apparatus showing difierences of onc-nillionth of a degree Centigrate, and he may eveo believe that he is measuring temperature to this degrce of nicety. A worker in the secund department, unless endowed with an exceptionally optimistic temperament, will probably net profess to measure teninerature to nearer than the nnethousandth of a degree, and that only between the freezing and boiling points of water. Itere I shall consider almost exclusively the question of the determination of temperature in alsolute measure.

The first regiuisite is a normal scale to which all measure. ments can be referred. An joleal scale should he perfect in theory, and easily and exactly realivable in practice. From the former point of view, Lord Kelvin's absolute thermodynamic scale is generally regarded as facile prinicps. In the meantime, however, it fails to satisfy the second con. dition. The International Committec of Weights and Wea. sures, representing all the leading Powers, including (;reat Britain, accordingly selected in $18 \mathrm{~S}_{7}$ for the normal scale that of the hydrogen constant-volume thermometer, the gas when at $0^{\prime \prime} \mathrm{C}$. to be under the pressure of 1 metre of mer. cury uncler standard conditions; on this scale equal incre. ments of temperature answer to equal increments of pressure. Apparently the choice was due mainly to two considerations, viz. the very low freezing point of hydrogen, and the exist. ence of theoretical and experimental grounds for believing its scale to approach Lord Kelvin's absolute scale more nearly than that of any other conmon gas. Whether hydrigen will prove a managcalle substance at high temperatures secms open to some drubt. Failure in this respect would be a serious drawback, in vieu of the rapidly increasing iniport. ance of high temperature measurements.

After the choicc of a normal scale, we are next concerned with its relationshijes to other scales that are, or have been previously, in use. Here, however, one difficulty is conspicu. ously present. Nothing is commoner than such a statement as that a certain temperature was nbserved on the scale of the air thermomcter; lut there are air thermometers and air thermometers. (Juite apart from the distinction between constant volume and constant pressure instruments, there are questions as $1(2)$ the pressure at $0^{3} \mathrm{C}$., the purity' of the air, the sufficiency or insufficiency of the corrections applied to the observed readings, and a host of others. In most investigrations thermometry' is but a means to an end, and ob. servers are apt to treat somewhat lightly of preliminaries which are not of greneral interest. On the other hand, an obserser is very apt to attach undue significance to the agree. ment between the scveral observations he nakes, overluoking the fact that in thermometry such agreenent need imply no 
more than uniformity in the conditions and in the method of experiment. For these several reasons, in translating old temperature observations into the normal hydrogen scale, it would in general be a waste of labour to aim at the degree of accuracy possible in the best thermometric work.

Whilst the exact determination of other scales in terms of the hydrogen scale is from a historical standpoint less important than might appear at first sight, it is still rendered essential by the fact that for many practical purposes the hydrogen ther mometer is inconvenient, and is unlikely to supersede other forms.

The most exact scale comparisons are doubtless those made at Servres, under the auspices of the international committee of weights and measures. These are described, with the exception of the most recent, in Dr. Guillaume's "Thermométrie de Précision," a work which all really interested in exact thermometry should study for themselves. Air being a composite medium, and so presumably less suitable for the basis of an exact scale than the elementary. gases, has applarently not been dealt with at Sevres; but the work there has included the comparison of the hydrogen, nitrogen and carbonic acid scales, espe cially of the first two. The investigation covered, in the first instance, the range $-25^{\prime \prime C}$. to $+100^{\circ} \mathrm{C}$., and was executed with great care by Dr. Chappuis. In point of time it preceded and, in fact, led up to the adoption of the hydrogen scale. The comparison of the gas scales was not direct, but through the intermediary of mercury thermometers. From the data on p. 258 of Guillaume's "Thermométrie," one learns that within the range $0^{\circ}$ to $100^{\prime \prime} \mathrm{C}$. the difference between the hydrogen and nitrogen scales does not cxceed $0^{\circ}$ or I C., but at $-25^{\circ} \mathrm{C}$. it amounts to about $0^{\circ}$. 0 r6. The differences between the hydrogen and carbonic acid scales are five or six times as large as these The hydrogen temperature is algebraically less than the nitrogen or carbonic acid temperatures between o and $70^{\circ} \mathrm{C}$., but algebraically greater at temperatures below $0^{\circ} \mathrm{C}$. In (iuillaume's opinion it is probable that ordinary (constant volume) air thermometers rive a scale near that of nitrogen, but lying somewhat on the side of the carbonic acid scale, i.c. more remote from hydrogen. The probable error in I)r. Chappuis' comparisons is given as $\pm 0^{\circ} \mathrm{OOI}$ between $0^{\circ}$ and $50^{\circ} \mathrm{C}$., and twice or thrice as great at either $+75^{\circ} \mathrm{C}$. or $-25^{\circ} \mathrm{C}$

The differences between the several gas scales presumably increase as the temperature falls, but probably never become large. At all events, in 1896 Holborn and Wien (Wied. Ann., vol. lix., 1896, p. 213), using constant volume thermometers (with, however, an initial pressure of only one atmosphere at $0^{\circ} \mathrm{C}$.), found the hydrogen thermometer to read only about $0^{\prime \prime} \cdot 6$ C. higher than the air thermometer at $-190^{\circ} \mathrm{C}$., a temperature close to the freezing point of air. Ten years carlier Olszewski found a difference of about $i$ "between the hydrogen ancl nitrogen scales at $-\mathrm{I}_{5} 0^{\circ} \mathrm{C}$.; but his thermometry was probably less exact. With only Olszewski's results before him, Guillaume infers that the hydrogen scale is almost certain to agrec closely with the absolute scale, even at $-220^{\circ} \mathrm{C}$; ; and Ilolborn and Wien's observations lead them to a somewhat similar conclusion. Recent comparisons hy Olszewski of hydrogen and helium thermometers (NATURE, vol. liv. Pp. 378 and 544) are strongly confirmatory.

For every-day use, unfort unately, gas thernometers are somewhat cumbrous. The international committee accordingly as signed an important place in their programme to the determin ation of the relations between the hydrogen scale and that of the glass-mercury thermometers which they have selected as working standards. The thermal expansion of glass, though smail, is not negligible compared to that of mercury, and varies in different kinds of glass. The international committee ac cordingly selected one special kind of glass, French verre dur, as standard. The selection of the glass does not alone suffice to fix the scale. No glass has yet been discovered whose hehaviour is decided wholly by the existing conditions. When a thermometer after exposure to a temperature of $50^{\circ} \mathrm{C}$. is placed in ice, it reads lower than it would have done prior 10 the exposure, and this depression of zero, as it is called, increases to a certain extent with the duration of the previous heating. It is thus necessary for high accuracy to decide on a uniform plan of dealing with this source of uncertainty. The plan adopted by the international committee is to refer every reading of at thermometer to a zero determined immediately after the reading. Under certain circumstances enough is known of the behaviour of verre dur to permit of the substitution for the actual zero observation of results extracted from a table of zero depressions. After a reading is taken with a zerre dur thermometer, a variety of corrections have to be applied. These are necessitated by inequalities in the bore or errors in graduation, by the influence of the external pressure exerted by the atmosphere and the in. ternal pressure exerted by the mercury. Verification at Stires consists in evaluating and tabulating all the necessary corrections. After these corrections are applied, the result represents the temperature on the natural verre dur-mercury scale. ${ }^{1}$ This scale has been compared with that of the hydrogen thermometer at Sivres from about $-38^{\circ} \mathrm{C}$. to $\div 200^{\prime \prime} \mathrm{C}$. Below $-10^{\circ} \mathrm{C}$. and above $100^{\circ} \mathrm{C}$. the comparison is probally less exact than betwcen these limits.

In considering the probable accuracy of temperature measure. ments made with verre dur thermometers, we have to take into account the consistency of readings taken with the same thermometer, the closeness of readings taken under the same conditions with different thermometers, and, from certain points of riew, the degree of accuracy with which readings can be reduced to the hydrogen scale.

The consistency of realings taken with a single ierre dur thermometer depends in the first instance to some extent on the success with which the correction tables have been constructed at Sevres; it varies to a large extent with the skill of the observer, the conditions of the experiment, and the temperature to be measured. The ordinary a'ere dur standard thermometer is divided to $0^{\circ} \cdot \mathrm{I} C$. and read by estimation, with the aid of a lens magnifying from ten to twenty times, to $0^{3} \cdot 001 \mathrm{C}$. This involves subdivision of a space into hundredths by eye, a feat which the skilled observers at Sèvres accomplish with marvellous accuracy, but which is far beyond the powers of the ordinary experinenter. In some instances use can be made of a micrometer, but this can hardly be employed unless temperature is practically stationary; and, when this is the case, troubles are apt to arise from capillary action in the mercury. The more remote the temperature to be measured from that of the sur rounding air, the greater, as a rule, is the proballe error of an observation. Thus, speaking generally, observations between $0^{\circ}$ and $40^{\circ} \mathrm{C}$ are those capable of the highest accuracy; and here it would appear that the mean results chtained on different occasions by skilled olsservers for a fixed temperature with a zerre dur thermometer may be expected to agree to within about $\pm \infty 1^{\circ} \mathrm{C}$.

At temperatures below $100^{\circ} \mathrm{C}$. the corrected readings of different rerre $d u w^{\circ}$ thermometers on the same occasion show apparently about as good agreement as is to be expected from the readings of a single verre dur thermometer exposed on different occa. sions to the same fixed temperature. At temperatures, however, approaching $200^{\circ} \mathrm{C}$. Dr. Chappuis found that the corrected readings of different verre dur thermometers might differ by as much as $0^{\circ} .05 \mathrm{C}$.

The accuracy with which the relation of the are dur to the hydrogen scale is known is hard to say. Lntil the Sivres com. parisons have been repeated at other places, under equally favourable condition:, there will always remain a certain amount of doubt as to the existence of possible local or temporary in. fluences. In the meantine, it is not altogether reassuring that a recent partial comparison of the hydrogen and z'ere dur scales at $10^{\circ}, 20^{\circ}, 30^{\circ}$ and $40^{\circ} \mathrm{C}$., hy Dr. Chappuis, gives results differing from those of the original comparison at Sivres by from 0.001 to $0^{\circ} \cdot 007 \mathrm{C}$.

From the above data two considerations naturally arise. At temperatures between $-20^{\circ} \mathrm{C}$. and $100^{\circ} \mathrm{C}$. the natural verre dur scale is probably that most easily and exactly realised in practice; and it is, perhaps, fully as correct to regard the present normal hydrogen scale as one deducible in a prescribed arbitrary way from the verre dur scale as to accept it as having any real physical existence. On the other hand, there is no such thing as a zerre dur scale, uniess we agree to neglect differences of tem. perature which are of the same order as differences actually found between different verre dur thermometers. At the present moment, for instance, we must apparently treat $0^{\circ} .05 \mathrm{C}$. as a negligible quantity in temperature measurements at $200^{\circ} \mathrm{C}$. if we are to extend the verre dur scale to that point. It has to be borne in mind that identity in the chemical constitution of thermometer glass may not necessarily imply identity in temperature scale.

1 For any natural glass-liquid scale, thermometer degree divisions include equal volumes of the bore.

NO. I 500, VOI.. 58 ] 
Age or prolonged annealing may introduce an appreciable change in physical properties.

In addition to the work already referred to, a comparison has been made at Sèvres of the hydrogen scale with the natural scales of low range glass-alcohol and glass-toluene thermometers. At $-70^{\circ} \mathrm{C}$. on the hydrogen scale the toluene temperature is $-56^{\circ} .63 \mathrm{C}$., as against about $-63^{\circ} \mathrm{C}$. on the alcohol scale. Notwithstanding its greater contraction of scale at low temperatures, toluene is preferred by Dr. Chappuis to alcohol, on the ground that the latter is much more difficult to get of uniform purity. At $-70^{\circ} \mathrm{C}$. differences of as much as $1^{\circ}$ were observed in thermometers filled with alcohol supplied as pure by different first-rate chemists. Even with toluene thermometers, $0^{\circ}$ or $\mathrm{C}$. appears the limit of accuracy to be hoped for. English alcohol thermometers, I should explain, are not, as a rule, constructed to give temperatures on the glass-alcohol scale. The degree divisions are shortened as we go down the scale, in such a way as to make the thermometer, when exposed to freezing mercury, read $-37^{\circ} \cdot 9 \mathrm{~F}$; this being the air thermometer temperature for freezing mercury according to Balfour Stewart's determination.

The thermometric work at the German Reichsanstalt ${ }^{1}$ has included the comparison of the verre dur scale with that of several German glasses, notably the Jena glasses I6rir and 59 ir. The former glass is fairly similar in character to verre our; the latter is a boro-silicate glass capable of resisting very high temperatures, and showing exceptionally small depression of zero. Thermometers made of it, with compressed gas above the mercury to prevent boiling, supply a convenient means of measuring temperatures up to $500^{\circ} \mathrm{C}$. or even $550^{\circ} \mathrm{C}$. In such high temperature measurements it is often difficult to avoid having a long mercury column emergent above the bath or other source of heat whose temperature is in question. The consequent error can be found apparently with great accuracy by means of a special form of long bulb thermometer ("Fadenthermometer"). Dr. Guillaume, who apparently anticipated the Reichsanstalt observers in the idea, has curiously enough found it foreshadowed in the Phil. Trans. for 1777 . Using the "Faden-thermometer," the Reichsanstalt observers apparently claim an accuracy of $\mathrm{O}^{\circ} \cdot \mathrm{I}$ C. in comparisons made in a well-stirred bath at $500^{\circ} \mathrm{C}$. They claim, however, an accuracy of $0^{\circ} .02 \mathrm{C}$. in comparisons of Jena glass thermometers with the air thermometer between $100^{\circ}$ and $300^{\circ} \mathrm{C}$. Until these results are confirmed or similar accuracy is claimed by the Sèvres observers, a chronicler may perhaps be pardoned an attitude of reserve.

Even with the aid of compressed gas, the range that can be covered by a mercury thermometer is somewhat limited, in view of modern requirements; and within that range there are many cases in which other means of measuring temperature are preferable. Nearly every property of every natural substance is modified by heat, so that the possible ways of measuring temperature are practically innumerable. Several of the ways that have been proposed for measuring high temperatures are very ingenious and may have a great future before them ; but the methods that have actually been utilised to an appreciable extent are but few. Of these the two that have been most to the front of late years have depended on the measurement of electric resistance and electromotive force respectively. The former method we may regard as embodied in the platinum resistance thermometer. Its introduction and the improvements it has undergone are due mainly to Prof. Callendar and $\mathrm{Mr}$. E. H. Griffiths, while its application to the determination of melting points of metals and alloys is largely due to Mr. C. T. Heycock and Mr. F. H. Neville. A clear description of the necessary apparatus and the mode of graduating platinum thermometers was given by Mr. Griffiths in NATURE, November 1895, p. 39. The essential fact is that a piece of platinum wire, suitably protected, is exposed to the temperature it is desired to measure, and its electrical resistance is found by a Wheatstone's bridge method. If $R_{1}$ be the resistance in steam, $R_{0}$ in ice, $R$ at any other temperature, then

$$
\not p t \equiv 100\left(\mathrm{R}-\mathrm{R}_{0}\right) \div\left(\mathrm{R}_{1}-\mathrm{R}_{0}\right)
$$

is termed the "platinum temperature." In common use $p t$ is employed only to deduce a quantity $t$, connected with it through the relation

$$
t-p t=\delta\left\{(t / \mathrm{IOO})^{2}-(t / 100)\right\},
$$

where $\delta$ is a constant, so chosen that $t$ equals $444^{\circ} 53$ when the

I Described in various memoirs in the Reichsanstalt's Wissens. Abhandl. and in the Zeitschrift für Instrumentenkunie.

NO. I 5OO, VOL. 58] platinum wire is at the temperature of the vapour of sulphur boiling under standard pressure.

The investigations of Callendar, Griffiths, Heycock and Neville show that the values obtained in this way for $t$, over a range of at least $1000^{\circ} \mathrm{C}$., are very close in different samples of platinum wire, so that $t$ represents temperature on what is at least very approximately a definite fixed scale. Further, Prof. Callendar found that the scale so arrived at approximates very clcsely to that of the air thermometer (at constant pressure) over at least the range $0^{\circ}$ to $600^{\circ} \mathrm{C}$. ; whilst the values of $t$ obtained by Messrs. Heycock and Neville for the melting points of silver, gold and copper, lie pretty close to the corresponding air temperature results obtained by Holborn and Wien at the Reichsanstalt.

If the wire of all platinum thermometers possessed the same value of $\delta$, then every platinum thermometer would give the same $p t$ when exposed to the same temperature $t$. We should then have a definite independent platinum scale, precisely as we now have a definite verre dur mercury scale between $0^{\circ}$ and $100^{\circ} \mathrm{C}$.

In reality, however, $\delta$ varies considerably-over at least 25 per cent. -in existing platinum thermometers, so that the present use of the term "platinum temperature" is open to criticism.

The question as to what is the best formula for use in platinum thermometry has been discussed by Mr. Hamilton Dickson recently in the Phil. Mag. (December I897, p. 445, and June 1898). After considering Prof. Callendar's principal formulæ, and others suggested at one time or another by him and Mr. Griffiths, Mr. Dickson decides in favour of the species

$$
(\mathrm{R}+a)^{2}=p(t+b),
$$

where $a, b, p$ are constants, and $t$ is the temperature answering to a resistance $R$ in the platinum wire. Mr. Dickson applies this formula to Prof. Callendar's original comparison with the air thermometer, to certain melting point determinations by Prof. Callendar and Mr. Griffiths, and to low temperature com. parisons by Profs. Dewar and Fleming and by Messrs. Holborn and Wien.

Determining the constants in the several cases by the method of least squares, he finds the probable divergence of observed and calculated values to be of the order $0^{\circ} \cdot 25 \mathrm{C}$

The formula approved by Mr. Dickson is really of the type

$$
t=a+b \mathrm{R}+c \mathrm{R}^{2}
$$

employed previously by Holborn and Wien in discussing observations made by them at the German Reichsanstalt. These gentlemen, perhaps owing to their less exact method of determining the constants, claim for their formula accuracy only of the order $\mathrm{I}^{\circ} \mathrm{C}$. Their comparison with the air thermometer extended down to $-190^{\circ} \mathrm{C}$, so that it seems in any case a valuable tribute to the suitability of platinum thermometers for the measurement of low temperatures.

At high temperatures Holborn and Wien's experience of the platinum thermometer was not very favourable, the wire showing appreciable permanent changes. As Mr. Griffiths, how. ever, points out, these changes occurred at temperatures to which platinum thermometers of the type he approves have frequently been exposed without any apparent ill effect. The preference expressed by Holborn and Wien for thermo-electric methods thus perhaps carries less weight than it might seem to deserve at first sight. It would certainly appear, as pointed out by Mr. Griffiths in NATURE, vol. liii. p. 390, that the determinations of the melting point of copper, about $1080^{\circ} \mathrm{C}$., by Heycock and Neville, with a variety of different platinum thermometers, agree considerably better amongst themselves than the corresponding results obtained by Holborn and Wien with thermo-couples.

Be this as it may, there can be no doubt that thermo-couples are very convenient instruments for high temperature measurements, and they have had hitherto a considerably wider use than platinum thermometers.

The physical quantity whose variations in the thermo-couple give temperature variations, is the total electromotive force in a circuit. The mainly active part of the circuit consists of two metals, one of whose common junctions is usually kept at a known fixed temperature, the other being exposed to the tem. perature it is desired to measure. The most widely used couple of late years has been Le Chatelier's, in which one metal is platinum, the other an alloy of platinum with rhodium (Io per cent. rhodium). The substitution of iridium for rhodium is not 
uncommon. Holborn and Wien have compared the Le Chatelier couple with the air thermometer at the Reichsanstalt up to $1450^{\circ} \mathrm{C}$. In Wied. Ann. vol. lvi. p. 364, they say that the readings of different thermo-elements may be expected to agree within $\pm 5^{\circ}$ at $1000^{\circ} \mathrm{C}$., while different observations with the same instrument agree better than this. They also say that properly prepared thermo-elements have remained unaltered for years, whether unemployed or subjected to frequent temperature changes, always provided they are not exposed to certain sources of contamination.

In their more recent low temperature work, already referred to, Holborn and Wien made further use of thermo-couples, but the metals chiefly employed were apparently iron and constantan.

In translating measurements of E.M.F., E, into air temperature, $t$, Holborn and Wien employ an ordinary algebraic formula

$$
t=a \mathrm{E}-b \mathrm{E}^{2}+c \mathrm{E}^{3} \text {. }
$$

Here, as usual, $a, b, c$ denote constants, which may be determined by observations at three fixed temperatures.

The question. of the most suitable type of formula to be applied to thermo-electric data is discussed very fully by Prof. S. W. Holman in the Phil. Mag. for June I896. The three types he advances as most deserving of notice are

$$
\begin{aligned}
& \mathrm{E}=\left(\tau-\tau_{0}\right)\left\{a+b\left(\tau+\tau_{0}\right)\right\}, \\
& \mathrm{E}=m\left(\tau^{n}-\tau_{0}{ }^{n}\right), \\
& \mathrm{E}=m t^{n} .
\end{aligned}
$$

In all $\mathrm{E}$ represents E.M.F, $m$ and $n$ constants to be determined by reference to fixed points, $\tau$ and $\tau_{0}$ temperatures of hot and cold junctions measured from alsolute zero, $t$ ordinary Centigrade temperature of hot junction (the cold junction being supposed in ice). The first or algebraic type, in a special form, is usually associated in this country with the name of Prof. Tait. The second type is called by Prof. Holman the exponential, and the third the logarithmic (as lending itself readily to logarithmic calculation). The three types are applied by Prof. Holman to what he regards as the most notable series of recent observations. In addition to the high temperature observations of Holborn and Wien, already referred to, he considers a number of comparisons of platinum and platinum-iridium couples with constant-pressure air thermometers made by Barus in America, and less extensive series by other observers in France and Germany. Of the three types of formulæ, the algebraic proved the least suitable for application to a wide temperature range.

In a later paper in the Phil. Mag. (vol. xlii., 1896, p. 37), Prof. Holman, with Messrs. Lawrence and Barr, apply the three above specified formulæe to observations of their own with couples of platinum and platinum-rhodium at the melting points of aluminium, silver, gold, copper and platinum. The constants in the formulæ were determined from the same three fixed points, viz. the ice point, the boiling point of sulphur at standard pressure, and the melting point of gold. For the second point Callendar and Griffiths' value $444^{\circ} .53 \mathrm{C}$. was accepted, and for the third point Holborn and Wien's mean result $1072^{\circ} \mathrm{C}$

Observations were taken at the boiling points of water and naphthalin, as well as at the melting points of the several metals. The temperatures calculated from the three formula agree closely for the copper point-which lies near the gold pointand fairly closely for the silver point. For the naphthalin point the calculated values differed from the true air scale temperatures by from $4^{\circ}$ to $12^{\circ}$, and the errors in the calculated values for the steam point were fully as large. If the authors are correct in their opinion, "so far. ... as constant or variable instru. mental errors are concerned, it is believed that no error beyond $0^{\circ} .5$ to $1^{\circ} \mathrm{C}$. exists in the results," we must conclude that further inquiry into thermo-electric methods is highly desirable.

Thermo-electric methods lend themselves fairly readily to the study of gradual temperature changes; the spot of light reflected by the mirror of the galvanometer measuring the E.M.F. being thrown either on a screen or on a photographic plate actuated by clockwork. Prof. Roberts-Austen (Roy. Soc. Proc., vol. xlix., I $89 \mathrm{I}$, p. 347) has inaugurated investigations by this method ${ }^{1}$ into

1 Since this article was written there has appeared in the Phil. Mag. for July 1898 , an interesting paper by Mr. A. Stansfield, describing improvements in Prof. Roberts-Austen's recording pyrometer, and discussing thermoelectric results. $\mathrm{Mr}$. Stansfield obtains $\mathrm{E}=a \tau+b \log \tau+c$, for the relation between E.M.F. and temperature, measured from the absolute zero. His melting points agree well, on the whole, with the determinations of Heycock and Neville.

$$
\text { NO. I } 500 \text {, VOL. } 58]
$$

the phenomena accompanying solidification of metals. Prof. Callendar, on the other hand (Trans. Roy. Soc. of Canada, 1897, p. 34), has recently applied the platinum thermometer in the continuous registration of the changes of earth, water and air temperatures; and, unless my memory deceives me, bare wire resistances have been used previously for the last-mentioned purpose

Thermo-electric and electrical resistance methods are also specially applicable to the measurement of minute temperature differences. As examples of this application, we may take the bolometer of Langley and the radio-micrometer of Boys (Phil. Trans., I889, p. I 59). The former instrument in its most approved shape-as in use at the Astrophysical Observatory at Washington-has been described very recently by Prof. Langley himself (The Smithsonian Institution, 1846-96, pp. 419-442, Washington, 1897). Its main use at Washington is in mapping out the infra-red spectrum and determining the intensity of the solar radiation at different wave-lengths. It is simply an electrical resistance thermometer, the resistance being that of a " metallic tape usually about $\frac{1}{3}$-inch long, but narrower and far thinner than a human hair . . . this, at present, may be arranged to record changes of temperature as small as one-millionth of a degree." Prof. Langley has devised the means of producing a uniform relative motion of the bolometer and solar spectrum, and obtaining an exact photographic record of the varying heating effect; and in this way he has apparently enormousiy reduced the labour of mapping the spectrum.

The radio-micrometer, on the other hand, consists essentially of a thermo-electric circuit-the principally effective junction being that of bismuth and antimony-which is suspended by a quartz fibre and is capable of rotation in an intense magnetic field. It is especially suitable for measuring the radiation from a distant or feeble source of heat, the radiation being received on a metal surface in immediate connection with the bismuth antimony junction. The delicacy of the instrument varies greatly with the shape of the circuit and the fineness of the quartz fibre suspension. According to Mr. Boys, it would be possible with the most approved pattern to detect with certainty " a temperature difference of less than one two-millionth of a degree Centigrade." Whether this has been realised in practice, I do not know.

A differential radio-micrometer was employed some years ago by Mr. W. E. Wilson and Mr. P. L. Gray (Phil. Trans. A, I894, p. 36I) in experiments in which solar radiation was balanced against the radiation from a strip of platinum heated to various known temperatures. The object of the research was to determine the mean effective temperature of the sun. The method is one which would seem capable of numerous useful applications.

As already stated, thermo-electric and electrical resistance methods are by no means the only ones, in addition to gas thermometry, for which high accuracy is claimed in high temperature measurements. There is, however, only one other method to which I shall refer here, viz. the expansion of solids. This is, of course, a very old method, and is generally employed only for commercial purposes for which high accuracy is not aimed at. In I891, however, Dr. Joly applied the principle in a new special form of instrument, the meldometer, for which high accuracy is apparently claimed as a means of determining melting points. The essential part of the instrument is a thin strip of platinum, kept stretched by a spring and heated as required by an electric current. A minute quantity of the substance under examination is placed on the strip, whose temperature is raised until the substance melts. There is delicate means of measuring the lengthening of the strip, and the corresponding temperature is deduced with the aid of a preliminary calibration, based on observations at two or three known melting points. The meldometer has been used by Prof. Ramsay and $\mathrm{Mr}$. Eumorfopoulos (Phil. Mag., vol. xli., I896, p. 360) in determining the melting points of a large number of salts, and these observers seem to think highly of it. A meldometer strip was also the source of heat, whose radiation was compared with that of the sun in the experiments of Messrs. Wilson and Gray already referred to. Having had no personal experience of the meldometer, I can only say that I should hardly expect it to rival in accuracy either the thermo-couple or the electrical resistance thermometer; but the smallness of the quantity of material required, is unquestionably a recommendation to its use in determining the melting points of rare or precious substances.

C. CHREE. 